\title{
FUNCIONAMIENTO NORMAL Y AUMENTADO DE LA GLÁNDULA TIROIDES EN EQUINOS
}

\author{
JÓSE HENRY OSORIO ${ }^{1}$ \\ FELIPE RAMÍREZ ECHEVERRY²
}

Recibido el 10 de abril de 2012 y aprobado el 22 de agosto de 2012

\section{RESUMEN}

Objetivo: Describir y analizar el funcionamiento normal de la glándula tiroides en equinos y los factores que aumentan en ellos los niveles de hormonas tiroideas. Materiales y métodos: Mediante la revisión de la literatura disponible de los últimos 50 años en las bases de datos BBCS-LILACS, fuente académica, IB-PsycINFO, IBSSCI, IB-SciELO, Scopus y Scirus, al igual que artículos históricos, textos y referencias citadas en trabajos publicados.

Resultados: la información obtenida relacionada con los objetivos propuestos en la presente revisión, permite clasificar en 4 secciones a saber: síntesis y secreción de hormonas tiroideas; transporte y metabolismo; funciones; hipertiroidismo en los equinos. Conclusión: La glándula tiroides juega un papel importante, como productora de hormonas tiroideas, las cuales son necesarias para la diferenciación celular y crecimiento del organismo. El buen funcionamiento de las vías metabólicas depende de estas hormonas, las que tienen efectos específicos sobre diferentes órganos, manteniendo la homeostasis en todos los tejidos.

\section{PALABRAS CLAVE}

Equinos, hormona tiroidea, metabolismo.

\section{NORMAL AND INCREASED FUNCTIONING OF THYROID GLAND IN EQUINES}

\section{ABSTRACT}

Objective: to describe and analyze the normal functioning of the thyroid gland in equines and the factors which increase the thyroid hormone levels. Materials and methods: information from the last 50 years included in the BBCS-LILACS, Fuente Académica, IB-PsycINFO, IB-SSCI, IB-SciELO, Scopus and Scirus, data bases as well as historical articles, texts and references cited in work published to date were analyzed. Results: important information related to the objectives 
proposed in the present review was found and analyzed. It was then divided into two sections as follow: synthesis, liberation and metabolism of thyroid hormones; factors that modify the thyroid hormone levels. Conclusion: the thyroid gland plays an important role producing thyroid hormones which are necessary for cellular differentiation and organic growth. The adequate functioning of metabolic ways depends on these hormones, which have specific effects on different organs maintaining homeostasis between all the tissues.

\section{KEY WORDS:}

Equines, thyroid hormone, metabolism.

\section{INTRODUCCION}

La glándula tiroides tiene dos orígenes diferentes embriológicos: Divertículo tiroideo y cuerpo timobraquial (tejido ectópico) (Toribio \& Duckett, 2004). La primera se origina del endodermo de la laringe primitiva, luego se mantiene como un conducto estrecho al crecer y se denomina conducto tirogloso el cual finalmente se convierte en un pedúnculo sólido de células foliculares las cuales son responsables de la síntesis de tiroglobulina y de hormonas tiroideas (THs). (Toribio \& Duckett, 2004). A partir de los cuartos arcos braquiales se origina el cuerpo timobraquial, donde se desarrollan las células para foliculares o células $\mathrm{C}$, denominadas como fuente de la hormona tirocalcitonina (Sisson \& Grossman, 2000). Tan pronto como transcurre la ontogénesis la función tiroidea comienza, pero el metabolismo continúa siendo basal, las estructuras hipotalámicas y el sistema pituitario portal es organizado para mantener el eje hipotálamo-pituitariotiroides (HPT) funcional (Toribio \& Duckett, 2004). La glándula tiroides se encuentra dorsal a la tráquea a nivel del tercer y sexto anillos, justo distal a la laringe, es de contextura lisa y firme, bilobulada donde ambos lóbulos se conectan por un istmo estrecho que contiene tejido fibroso, mide aproximadamente $2.5 \mathrm{~cm} \times 2.5 \mathrm{~cm} \times 5 \mathrm{~cm}$, con un peso aproximado de $0.04 \mathrm{~g} / \mathrm{kg}$ del peso corporal (Blomme et al, 1999).

Histológicamente la glándula está compuesta por células cúbicas en el epitelio bajo organizado en folículos. Las células epiteliales producen tiroglobulina, una glicoproteína que contiene residuos múltiples de tiroxina (Brehaus, 2011). En la mayoría de caballos saludables la glándula tiroides no es visible pero puede ser palpable como una 
estructura firme y movible. Posee una coloración gris rosácea, con una consistencia intermedia. El peso de la glándula en gramos de tejido tisular en comparación a kilogramos de masa corporal es mayor para fetos y potros (es decir $0.28 \mathrm{~g} / \mathrm{kg}$, en un rango de 0.12 a $0.67 \mathrm{~g} / \mathrm{kg}$ ), disminuyendo progresivamente con la edad. La relación con la masa corporal para adultos es en promedio 0.08 $\mathrm{g} / \mathrm{kg}$ con un rango entre 0.01 a $0.15 \mathrm{~g} / \mathrm{kg}$. El peso total de una masa glandular normal de un potro recién nacido es alrededor de $15 \mathrm{~g}$ (Toribio \& Duckett, 2004). La irrigación de la glándula tiroides está formada de la siguiente manera: 2 arterias tiroideas superiores, que son ramas de la carótida externa, cada una se trifurca en interna, externa y posterior, y 2 arterias tiroideas inferiores, son ramas de la subclavia, Cada una de ellas se trifurca en inferior, posterior, profunda (Sisson \& Grossman, 2000).

En algunas ocasiones es posible encontrar una arteria tiroidea media o tiroidea de Neubauer, cuyo origen se da en la aorta 0 en el tronco braquiocefálico, sus ramificaciones tortuosas se dirigen inicialmente por la superficie de la glándula y posteriormente se dirigen hacia el interior de su espesor (Gray H, 2000). La circulación venosa forma el plexo venoso tiroideo alrededor de la glándula, las venas que lo conforman se encuentran clasificadas de la siguiente manera: Venas tiroideas superiores, correspondientes a las arterias del mismo nombre, desembocan en la yugular interna directamente en algunos casos, en otros, lo hace en el tronco tirolinguofacial (Sisson \& Grossman, 2000); venas tiroideas inferiores, se originan en el borde inferior de la tiroides desembocan en la yugulares internas y en el tronco braquiocefalico izquierdo (Sisson \& Grossman, 2000); y venas tiroideas medias, localizadas entre las superiores y las inferiores desembocan en la yugular interna (Gray $\mathrm{H}$, 2000).

Es importante resaltar que las venas tiroideas son avalvulares, probablemente por su ubicación anatómica con respecto al corazón (Sisson \& Grossman, 2000). La circulación linfática de la glándula tiroides se constituye por un plexo peritiroideo el cual está dividido en: linfático descendente, que filtra la linfa en ganglios que están ubicados en la cara anterior de la tráquea (Sisson \& Grossman, 2000) y linfático ascendente, que filtra en los ganglios prelaríngeos y en los laterales del cuello (Gray H, 2000). La inervación de la glándula se conforma de el nervio simpático cervical porción del ganglio cervical medio y dos nervios laríngeos provenientes del superior recurrente (Gray, 2000). 


\section{SÍNTESIS Y SECRECIÓN DE HORMONAS TIROIDEAS}

El tejido tiroideo se forma de folículos de células epiteliales alrededor del lumen con un contenido coloide. Estos folículos se agrupan en una glándula discreta, la glándula tiroides. El epitelio celular de la tiroides toma el yodo y secreta la proteína tiroglobulina al interior del lumen de tales folículos, donde se encuentran más de 100 residuos de tirosina por molécula de tiroglobulina, luego de cierto número de residuos son yodados al grupo hidroxil fenólico a la forma 3-yodotirosina (T1) y 3,5-diyodotirosina (T2) (Hulbert, 2000). La mayor función de la tiroides activa es atrapar y conservar el yodo alcanzando un alto gradiente de concentración. El yodo puede ser absorbido en forma soluble, (yodo $\left(\mathrm{I}^{-}\right)$), por la mucosa intestinal u otra superficie mucosa o piel descubierta. El yodo activo es transportado y concentrado al interior por un simposio de $\mathrm{Na}^{+} / l^{-}$. (Hulbert, 2000; Toribio \& Duckett, 2004). Dicho yodo captado es oxidado por una peroxidasa tiroidea en la presencia de un peróxido de hidrógeno y se incorpora al interior de los residuos de tirosina de la forma tiroglobulina para formar precursores inactivos de la T1 y T2. Posteriormente se arman parejas entre estas dos yodotironinas dando lugar a la tiroxina (T4) y a la triyodotironina (T3) (Gürbüz et al, 2005).

Las THs y sus metabolitos son moléculas reconocidas en el organismo por contener yodo y la mayoría de la masa molecular de ambas hormonas tiroideas está constituida por átomos de yodo (Hulbert, 2000.) Existe otra hormona conocida como T3 inversa (rT3) la cual también ejerce efectos tiróideos (Baragli et al, 2011). Mientras las hormonas no son requeridas por el organismo son almacenadas a modo de tiroglobulina, la cual dependiendo de la necesidad del organismo se libera a la sangre como T4 o como T3, después de un proceso de hidrólisis que se encarga de separarla. La T4 posee 4 átomos de yodo por cada molécula, mientras que, la T3 posee 3 átomos de yodo por cada molécula (Dittrich et al, 2011).

La mayoría de TH liberada a la circulación es T4, las concentraciones en suero de T4 total son 20 veces mayores que las concentraciones de T3 en suero. La síntesis hormonal y liberación son controladas por la disponibilidad del yodo y por la TSH (Christensen et al, 1997), La síntesis y secreción las THs es regulada por un sistema de retroalimentación negativo basado en el eje Hipotálamo-pituitaria-tiroides (HPT). La síntesis y secreción de la hormona tiroidea es incitada por la hormona estimulante de la tiroides tirotropina (TSH), la cual es una glicoproteína compuesta por 2 subunidades ( $\alpha$ y $\beta$ ) y es secretada por las tirotropinas de la glándula 
pituitaria (Brehaus, 2011; Toribio \& Duckett, 2004). La subunidad a es compartida por otras hormonas (hormona luteinizante y hormona folículo estimulante). La secreción de TSH de la pituitaria anterior (adenohipófisis) es controlada por los efectos de las neuronas hipotalámicas que desatan un tripéptido liberador de hormona tirotropina (TRH) (Hurcombe, 2011). La síntesis de tirotropina y la secreción es también controlada por retroalimentación negativa (inhibición a largo plazo) debido a la estimulación de las THs.

Las concentraciones de TSH dependen de la tasa de dispersión de las THs y los niveles de TSH en la circulación al igual que en la medida que T4 se convierte en T3. El hipotálamo también puede inhibir (inhibición a corto plazo) la secreción de TSH a través de la dopamina y la somatostatina liberada en el medio eminente. Las neuronas que producen TRH positiva están presentes en diferentes áreas del cerebro (Hyypp, 2005). Con el hipotálamo la división parvocelular del núcleo paraventricular contiene la mayoría de las neuronas TRH positivas, y sus proyecciones finales en la zona externa de la eminencia media. (Brehaus, 2011; Hurcombe, 2011) En la glándula pituitaria, T3 disminuye la respuesta tirotropa (secreción de TSH) una vez la glándula es estimulada por la $\mathrm{TRH}$, y en el hipotálamo la T3 disminuye la expresión del ARN mensajero de TRH al igual que la secreción.

En la pituitaria, T4 es convertida a T3 por la desyodinasa tipo II (Hurcombe, 2011). Para que la T4 pueda acceder a las neuronas del hipotálamo, debe ser transportada a través del plexo coloide hacia el ventrículo lateral ligada a la transtiretina (proteína de unión a T4), una vez en el cerebro T4 es convertida a T3 por la desyodinasa tipo II. (Toribio, 2011; Hurcombe, 2011) La TRH es liberada en la eminencia media del hipotálamo y a través del sistema pituitario portal alcanza la pituitaria anterior (Johnson, 2002). En la pituitaria, la interacción de TRH con los receptores específicos en los tirotropos inducen la liberación de TSH, y también induce la liberación de prolactina (Brehaus, 2011; Toribio \& Duckett, 2004).) El eje HPT puede ser inhibido por altas temperaturas y estimulado por bajas temperaturas. El estrés inhibe la producción de TSH a través de la liberación hipotalámica de somatostatina (Ge'rard et al, 1999). La inflamación suprime la secreción de TSH. Las citoquinas (interleuquina 1 y 6) y el factor $\alpha$ de necrosis tumoral inhiben la secreción de TSH y estimulan la secreción de somatostatina (Toribio, 2011). 


\section{TRANSPORTE Y METABOLISMO DE LAS HORMONAS TIROIDEAS EN EQUINOS}

La circulación de las hormonas tiroideas en la sangre, aparece de una manera pulsátil la cual es distinta según la especie (especie específico) con distintas variaciones ontogénicas, lo cual es responsable de la variación morfológica individual y del comportamiento sexual de cada animal (Crockford, 2008). La circulación de las THs es principalmente de T4, T3, y rT3. T4L y T3L son hormonas biológicamente activas, mientras que T3 y rT3 son productos de desyodación de T4. La T4 circulante es derivada directamente de la glándula tiroides. Sólo un 10\% a un $20 \%$ de la T3 circulante es secretada directamente de la glándula tiroides (Allermeier et al, 2011) En los caballos los porcentajes de T4 circulante ligado a la globulina fijadora de tiroxina equivale a un $61 \%$, ligado a prealbúmina fijadora de tiroxina un $22 \%$ y T4 fijada a albúmina un 17\% (Buff et al, 1997). La T3 también corre ligada a la globulina fijadora de tiroxina y albúmina pero no se liga a la prealbúmina fijadora de tiroxina. Estas hormonas son unidas de manera reversible a las proteínas transportadoras, quienes actúan como reservorios de $\mathrm{TH}$ (Kratzsch \& Pulzer, 2008).

Las hormonas ya sean ligadas o libres están listas para atravesar el endotelio capilar y ejercer sus efectos biológicos en los tejidos tisulares. La proteína fijadora tiene como propiedad determinar la actividad biológica de cada hormona (Buff et al, 1997). La T3 es mucho más potente que la T4 y tiene una vida media más corta. La tiroxina tiene mayor afinidad por las proteínas transportadoras, sin embargo la T3 se contacta con mayor facilidad a los receptores de los tejidos periféricos, ya que la tiroxina puede actuar algunas veces como pro-hormona (Geor, 2008). La vida media de la T4 en los caballos es de aproximadamente 50 horas. Una larga fracción de THs se encuentra ligada a proteínas plasmáticas, por lo tanto, los cambios en las proteínas fijadoras pueden alterar los resultados de las concentraciones totales de $\mathrm{TH}$ (Toribio \& Duckett, 2004). La degradación metabólica de la tironina después de la des-yodación incluye la des-aminación, la des-carboxilación y conjugación.

Las enzimas responsables de la producción de T4 y rT3 también lo son de su destrucción. Las tres clases de $5^{\prime}$ desyodinasas son las siguientes: Tipo l: Es encontrada principalmente en tejidos periféricos como la tiroides, el riñón y el hígado, es la responsable de la conversión de T4 a T3 y rT3, y es inhibida de forma no competitiva por el propiltiouracilo, su actividad es incrementada por la TSH y T3 y disminuida en hipotiroidismo. (Toribio \& Duckett, 
2004); Tipo II: Está localizada en el tejido de grasa parda, en el cerebro y en la glándula pituitaria, no se afecta por el propiltiouracilo, y su función principal es convertir T4 a T3 a nivel intracelular (Johnson et al, 2004). Su actividad se incrementa en el hipotiroidismo probablemente por el mantenimiento intracelular de las concentraciones de T3 debido a una baja en las concentraciones de T4 periféricas, primordialmente en el cerebro. (Toribio \& Duckett, 2004); Tipo III: Se encuentra en la placenta, desarrollo del cerebro y piel, su función principal es inactivar T4 y T3, convirtiendo T4 en rT3 y a T3 inactiva. (Toribio \& Duckett, 2004). Los metabolitos son excretados vía urinaria y algunos son conjugados e introducidos a la circulación enterohepática. La mayoría del yodo regresa a la glándula tiroides (Toribio \& Duckett, 2004).

\section{FUNCIONES DE LAS HORMONAS TIROIDEAS EN LOS EQUINOS}

La principal acción de las hormonas tiroideas es estimular el consumo de oxígeno. Las THs estimulan la síntesis y el catabolismo de proteínas, ayudan a regular el metabolismo lipídico, el metabilismo basal y la producción de calor corporal (Hulbert, 2000). Estas hormonas no son esenciales para la vida, pero juegan un papel importante en el crecimiento y maduración del organismo. Las acciones de las THs se dividen en genómicas y no genómicas (Brehaus, 2011). Las acciones genómicas son mediadas por receptores que requieren factores de transcripción nuclear que incrementa o disminuye la expresión de los genes que regulan la función celular (Brehaus, 2011). Las acciones no genómicas pueden ser iniciadas por los receptores de la membrana plasmática, dentro del citoplasma o la mitocondria. Tales acciones incluyen roles en la división celular, angiogénesis, transporte de proteínas, migración celular, agregación plaquetaria, síntesis de óxido nítrico y activación de la bomba de $\mathrm{Na} / \mathrm{k}$ (sodio-potasio), modulación de calcio ATPasa y cambio de $\mathrm{Na} / \mathrm{H}$, modulación de neuronas y $\mathrm{Na}$ miocitos, y actividad del receptor del factor de crecimiento epidermal (Cianchetta et al, 2010; Nagy et al, 2000).

La glándula tiroides contiene células parafoliculares, comúnmente referidas como células $\mathrm{C}$. Dichas células secretan factores que ayudan a regular la actividad de las células foliculares, también secretan calcitonina, un importante regulador de las concentraciones de calcio extracelular (Breuhaus, 2011; Rudi's et al, 2005). Los receptores de $\mathrm{TH}$ comienzan por la superfamilia de los receptores nucleares que trabajan como factores de transcripción. Los dos tipos de receptores son TR- $\alpha$ y TR$\beta$. La T3 puede ser transportada directamente al interior 
celular o derivada de T4 de manera intercelular (Hubert et al, 2007). Los receptores de tiroides interactúan con secuencias de ADN específicas (T3-específicas) regulando la expresión de los genes. El crecimiento y la termogénesis dependen de la presencia de THs. Las THs disminuyen la expresión de las subunidades $\alpha$ y $\beta$ de los genes de TSH y de TRH. (Baragli et al., 2011). De estos efectos en la expresión genética, la acción de T3 resulta en termogénesis, incrementando la expresión de proteínas asociadas con la fosforilación oxidativa (Clutterbuck et al, 2010). Aumenta el consumo de oxígeno, incrementa la síntesis de proteínas, incrementa la tasa metabólica, aumenta la absorción de carbohidratos y el metabolismo de la glucosa, la estimulación del crecimiento, maduración y eritropoyesis, incrementa el metabolismo lipídico y la conversión de colesterol en sales biliares, activa la lipasa lipoproteína, aumenta la sensibilidad del tejido adiposo para la lipólisis, estimula la tasa cardiaca, el gasto cardiaco y el flujo sanguíneo, incrementa la transmisión neural además del desarrollo cerebral y neuronal en los animales jóvenes (Toribio \& Duckett, 2004; Baragli et al., 2011).

Entre las funciones que cumplen las THs esencialmente se refieren al metabolismo y al desarrollo (Barsnick \& Toribio, 2011). Además de las funciones dichas anteriormente también actúan sobre el equilibrio de las mucoproteínas y liquido extracelular, ayudan en la formación de la vitamina A por medio de los carotenos, los cuales son indispensables para el desarrollo del sistema nervioso tanto central como periférico, intervienen en los procesos de contracción muscular y motilidad intestinal; participan en el desarrollo y erupción de las piezas dentales (Tahboub \& Arafah, 2009). Controlan la liberación y el uso de las hormonas del crecimiento, que son las encargadas de estimular al hígado a liberar (IGF-I) (Barsnick \& Toribio, 2011; Buff et al, 2007). Las hormonas tiroideas son requeridas para la maduración bioquímica, hipertrofia, y penetración capilar del cartílago en crecimiento. La triyodotironina puede actuar de forma indirecta para promover la condrogénesis por estimulación de la pituitaria para secretar y sintetizar la hormona del crecimiento (Clutterbuck et al, 2010). Las THs incrementan el crecimiento del esqueleto fetal por medio de los receptores de la hormona del crecimiento y el factor de crecimiento insulínico tipo I, luego la THs influencia el crecimiento y el desarrollo esquelético por la actividad local del eje somatotrófico (Toribio \& Duckett, 2004).

Las THs modulan los efectos de los receptores adrenérgicos (Buff et al, 2007). Los tejidos tienen una mayor respuesta a las catecolaminas b-adrenérgicas cuando las concentraciones de THs son altas, e 
inversamente cuando hay hipotiroidismo. Se ha identificado que cuando hay una disminución en la densidad de los receptores b-adrenérgicos en los animales hipotiroideos disminuyen las fijaciones del sistema Adenin ciclasa y por último la función del receptor es minimizada (Crockford, 2003). De igual forma las THs son necesarias para la formación normal y la estabilidad del citoesqueleto por medio de la migración y crecimiento neuronal. Las células del citoesqueleto son el principal sitio de acción de las THs, ya que, definen la arquitectura y motilidad celular (Buff et al, 2007). Un análisis por polimerización microtubular del desarrollo del cerebelo revela que la expresión de la familia de microtubulos asociados a proteínas deja 5 formas de tubulina que fueron reguladas por las THs (Rudi's et al, 2005). Los microfilamentos son grandes componentes de las células del citoesqueleto y están compuestos por fibrillas y haces de fibras de polímeros de la proteína mecano-química actina.

Las THs se encargan de regular dinámicamente la polimerización de actina en astrocitos por un proceso no genómico, pues poseen la capacidad de organizar la actina en el citoesqueleto y desarrollar el cerebelo rápidamente una vez que se logra regular la migración neuronal (Fitzgerald, Davison, 1998). Además de las THs el yodo también cumple una función importante a nivel del tejido ovárico, ya que este tejido ovárico no sintetiza yodo proteínas hormonales, por ende su actividad de tomar y almacenar yodo puede ser inhibida por fármacos como el tiocianato, perclorato y dosis excesivas de yodo, situación que es conocida como el efecto Wolff-Chaikoff, lo cual también ocurre en el tejido tiroideo (Slebodzi'nski, 2005). Las presencia de un transportador de $\mathrm{Na}^{+} / I^{-}$symporter (NIS), en los tejidos que no son de la tiroides, permite considerar ésta como una de las opciones más viables a través de la cual los ovarios y otras estructuras del organismo toman y acumulan el yodo; Sin embargo, existen otros aniones que también son transportados por el NIS como el technetio y el pertecnato, los cuales inhiben de manera competitiva la captación del yodo (Ge'rard N et al, 1999).

\section{HIPERTIROIDISMO EN LOS EQUINOS}

La tirotoxicosis se desarrolla como un desorden primario de la glándula tiroides principalmente. El hipertiroidismo primario se caracteriza por síntomas y signos correspondientes al exceso de THs donde las concentraciones de T4L o de T3 o ambas se encuentran elevadas y los niveles de TSH se encuentran suprimidos. Raras veces la tirotoxicosis se produce por una sobreproducción de TSH por parte de la glándula pituitaria 
con un crecimiento secundario de la tiroides e hiperfunción, lo cual se denomina hipertiroidismo central (Frank et al, 2002). Esta patología es de común presentación en animales de edad avanzada (más de 17 años) (Glover et al, 2009; Nicassio et al, 2008). Existen dos causas conocidas de hipertiroidismo central: tumores de la glándula pituitaria con excesiva producción de TSH (TSHomas) (Lucke \& Lane, 1984) y síndrome de resistencia de la glándula pituitaria a la hormona tiroidea. Tales desórdenes producen manifestaciones clínicas de tirotoxicosis con elevadas concentraciones en suero de T4L y T3, pero se distingue por los hallazgos críticos de los niveles de TSH en suero, ya sea que se encuentre normal o elevada (Frank et al, 2002). Se cree que los TSHomas exhiben dos características que los diferencian de los tirotropos normales, la primera que son una proliferación celular excesiva; la segunda que poseen una producción autónoma de TSH como poca respuesta de los controles reguladores (McDermott \& Ridgway, 1998; BeckPeccoz et al, 2009). El bocio es definido como no inflamatorio, no neoplásico aumento de la glándula tiroides, puede ser clasificado en hiperplasia y coloide. Pueden ser nodulares o difusos (Geor, 2010). Normalmente los niveles bajos de tiroxina se deben a una producción de TSH desde la pituitaria. La glándula tiroides responde funcionalmente a esta hormona poli-péptida por incrementeo del yodo fijado, así como por la síntesis y secreción de tiroixina (Doige, 1981).

Morfológicamente la estimulación de TSH produce una hipertrofia e hiperplasia de las células del epitelio folicular e incrementa la vascularidad de la glándula (Gerlach \& Aurich, 2000). Dichos cambios contribuyen al aumento de la glándula tiroides. Si el yodo es insuficiente o si la síntesis de tiroxina es baja, mucho tejido coloide puede estar presente y esta glándula puede continuar creciendo (Doige, 1981). Tal tipo de bocio es conocido como hiperplásico o parenquimatoso. El bocio fetal hiperplásico es el resultado de la estimulación de la glándula fetal por TSH. El tamaño del bocio fetal y el desarrollo de la hiperplasia se manifiesta como una variable dependiente del grado y la duración de la estimulación de TSH (Doige, 1981). Se cree que el bocio coloide representa la fase de involución del bocio hiperplásico. En este caso cuando el yodo es necesitado por el animal, los folículos acumulan coloide y crecen (Malinowski et al, 1996). De acuerdo a esta teoría se puede decir que el bocio coloide no es necesariamente asociado con hipotiroidismo (Doige, 1981). El adenoma es la neoplasia más común de la glándula tiroides de los equinos. El fenómeno va ligado a la edad avanzada (mayores de 16 años) (McDermott MT \& Ridgway, 1998). Es de carácter beningo, generalmente 
unilateral y no está asociada con disfunción tiroidea. Ocasionalmente la talla del adenoma puede requerir la escisión quirúrgica. El pronóstico es bueno. La hemitiroidectomía de la glándula afectada restablece las concentraciones de TH (Frank, 2002). Los adenomas provenientes de las células foliculares de la tiroides son clasificados en los de tipo papilar y los de tipo folicular (Toribio \& Duckett, 2004; Petersen \& Schoot, 2005).

La mayoría de los tumores provienen de las células epiteliales. Los tumores de células epiteliales son inmunohistoquimicamente positivos a tiroglobulina mientras que los tumores de células parafoliculares (células tipo c) y los derivados de ellos son positivos a calcitonina, a péptidos relacionados con el gen de la calcitonina (CGRP), cromogranina, enolasa neuro especifico (NSE) y sinaptofisina (Doige, 1981). El estudio confirma que los nódulos blancos de la tiroides ocurren frecuentemente en caballos de 20 o más años; de hecho en algunas ocasiones son hallazgos incidentales al incidir la glándula en las necropsias, los síntomas asociados con la hipersecreción ce calcitonina no se encontraban presentes. Su aparición no se relaciona con el sexo ni la raza de los animales (Ueki et al, 2004). La proliferación de tipo patológico de las células $\mathrm{c}$ se divide en hiperplasia, adenoma y carcinoma. La hiperplasia es una acumulación focal de un tamaño menor al de un folículo lleno de coloide, su diagnóstico debe darse cuando existe un aumento definitivo en el número de células de tipo $c$ en cada lóbulo de la tiroides al ser comparado con un grupo de control de animales de la misma edad (Frank, 2002). Las células $\mathrm{C}$ de los adenomas, bien diferenciadas, poseen un citoplasma abundante que es medianamente eosinofílico o claro en tinciones realizadas con hematoxilina eosina (HE) (Medica et al, 2011). Por su parte los carcinomas poseen más células que los adenomas de células $\mathrm{c}$, además las células que conforman el tumor son más pleomórficas (Toribio \& Duckett, 2004). Este tipo de tumores no aparenta ser funcional debido a que los caballos no manifiestan ninguna sintomatología referente a un exceso en la secreción de calcitonina y simplemente parecen ser una anormalidad relacionada con los caballos de edades avanzadas (Ueki et al, 2004). No existen reportes sobre hipertiroidismo en caballos asociado a una condición autoinmune (Messer et al, 1998) Los tumores suelen ocurrir en razas de bajo peso y en caballos de trabajo, son más frecuentes en caballos de edad avanzada que en animales jóvenes. Por otra parte la agregación celular tiene 3 clasificaciones: residuo ultimobraquial incrustado en el tejido tiroidal sin compresión de células adyacentes (Messer et al, 1998); hiperplasia nodular de residuo ultimobraquial que 
comprime las células foliculares adyacentes (Toribio \& Duckett, 2004); y adenoma del segmento residual ultimobraquial rodeado por una cápsula fibrosa (Toribio \& Duckett, 2004). Entre las manifestaciones clínicas más frecuentes se encuentran tremores, excitabilidad, taquicardia, taquipnea, sudoración, pérdida de peso a pesar de presentar un aumento en el apetito, temperamento hiperactivo, alopecia y caquexia (Ahmed et al, 2008). Los caballos que presentan tumores en la glándula pituitaria principalmente desarrollan síntomas como hirsutismo, letargia, laminitis, polidispsia y poliuria. Otros signos incluyen disminución de la fertilidad, depresión inmunitaria, hiperhidrosis, convulsiones, diabetes insípida, anovulación persistente, endometritis y pseudolactancia. (Durham, 2010; Walsh et al, 2009).

Diagnóstico. Los altos niveles de T3 y T3L, durante los 10 a 13 meses de edad se pueden asociar al aumento del uso de T4L o a cambios en la tasa de monodeionización de T4 o de T3 (Fazio et al, 2007). Las concentraciones de THs en plasma se encuentran elevadas, sin embargo éstas pueden aumentar por estados fisiológicos no asociados a signos clínicos anormales, como en la preñez debido a los altos requerimientos por parte del feto para su desarrollo (Allermeier et al, 2011). Se utilizan los métodos tanto directos como indirectos citados en la sección de hipotiroidismo, donde las concentraciones de las hormonas se encuentran por encima de los valores establecidos (Divers, 2008; Ramirez, 2010). La aspiración o biopsia simple puede ayudar a diferenciar los quistes, neoplasias, bocio hiperplásico, bocio coloide e inflamación (Toribio \& Duckett, 2004). Para las imágenes diagnósticas se utiliza el pertecnato (tectenium -99m) que es un componente usado para diagnosticar el mecanismo de captación del yodo. La imagen scintigráfica ha sido usada clínicamente para evaluar la glándula tiroides de los caballos. Se ha observado patrones anormales en el carcinoma de tiroides. La evaluación ultrasonográfica de las glándulas puede diferenciar estructuras sólidas quísticas, ha sido utilizada también para evaluar la morfología de la glándula tiroides (Frank, 2002). La scintigrafía es muy usada para la evaluación de la función tiroidea, la detección de enfermedades metastásicas y para medir el volumen de los tumores metabólicos en humanos y en pequeños animales, de igual forma se ha descrito su uso en caballos. Tal técnica es especialmente usada para determinar la función de la glándula y si hay diferencias de función entre los lóbulos, lo cual es de gran importancia al momento de tomar una decisión quirúrgica (hemitiroidectomía) (Breuhaus, 2011; Roser, 2008). 
Tratamiento. Si la neoplasia es diagnosticada y las concentraciones en suero de THs son normales y no hay todavía un agrandamiento de la glándula suficiente para comprometer la respiración o la ingestión de alimentos no es necesario remover las glándulas tiroides inmediatamente. Si las concentraciones de THs en suero son bajas, el caballo puede suplementarse con uno de los productos severos (Alberts et al, 2001). Si el caballo tiene hipertiroidismo o si las glándulas comienzan a aumentar de tamaño rápidamente, se debe considerar le remoción quirúrgica y comenzar con una terapia de soporte (Brehaus, 2011; Warner \& Beckett, 1998). Si se contempla la cirugía, se debe realizar antes de que las glándulas crezcan lo suficiente para complicar la remoción (Alberts et al, 2001). Si el tamaño de la glándula no es un problema, pero el caballo es hipertiroideo, se puede administrar propiltiouracilo oral para disminuir las concentraciones de THs circulantes. Este fármaco actúa inhibiendo la síntesis de THs por antagonismo de la peroxidasa tiroidea (la cual cataliza la oxidación de yoduro a yodo), inhibiendo la síntesis de tiroglobulina, inhibiendo el crecimiento de las células foliculares de la tiroides e inhibiendo la conversión de T4 a T3. Se administra a una dosis de $8 \mathrm{mg} / \mathrm{kg} / \mathrm{día}$, pero una vez que disminuyan los niveles séricos de THs se puede suministrar cada 48 horas.

El manejo del propiltiouracilo debe ser cuidadoso, el personal debe usar siempre guantes y máscara (Brehaus, 2011). Las circunstancias que requieren escisión quirúrgica tienen un mejor pronóstico cuando la condición es unilateral sin una anormalidad sistémica concurrente. Las complicaciones incluyen infección posquirúrgica, hemorragia, hemiplejia laríngea. Las glándulas paratiroides en los caballos generalmente no están conectadas con las glándulas tiroides por ende la hipocalcemia no es una complicación (Toribio \& Duckett, 2004). La tiroidectomía ha sido realizada en caballos y ponis. Se realiza anestesia ubicándose en posición dorsal y se procede a la escisión de la(s) glándulas tiroideas. Los caballos tiroidectomizados exhiben intolerancia al frío con escalofríos cuando el clima está a bajas temperaturas, letargia, reduce el consumo de comida, con tasas estáticas de crecimiento, disminución de la actividad sexual, engrosamiento de la piel de la cara, engrosamiento de los párpados, edema de las extremidades traseras, capa de pelo gruesa, ligera alopecia y desprendimiento tardío del pelo (Ueki et al, 2004). 


\section{BIBLIOGRAFÍA}

- Abraham, G.; Allersmeier, M.; Schusser, G.F.; Ungemach, F. R. (2011). Serum thyroid hormone, insulin, glucose, triglycerides and protein concentrations in normal horses: Association with topical dexamethasone usage. Vet J; 188: 307-312.

- Ahmed, O.M.; El-Gareib, A.W.; El-bakry, A.M.; Abd ElTawab, S.M.; Ahmed R.G. (2008). Thyroid hormones states and brain development interactions. Int. J. Devl Neuroscience 26:147-209.

- Alberts, M.K.; McCann, J.P.; Woods, P.R. (2001) Hemithyroidectomy in a horse with confirmed hyperthyroidism.J Am Vet Med Assoc 217 (7):1051-4.

- Baragli, P.; Sgorbini, M.; Casini, L.; Ducci M.; Sighieri C. (2011). Early evidence of the anticipatory response of plasma catecholamine in equine exercise. Equine Vet $\mathrm{J}$. 31:85-88.

- Barsnick, R.J.; Toribio, R.E. (2011). Endocrinology of the equine neonate energy metabolism in health and critical illness. Vet Clin Equine. 27: 49-58.

- Beck-Peccoz, P.; Persani, L.; Mannavola, D.; Campi, I. (2009). TSH-secreting adenomas. Best Pract Res Clin Endocrinol Metab. 23: 597-606.

- Blomme, E.A.; Sugimoto, Y.; Lin Y.C.; Capen, C.C.; Rosol, T.J. (1999). Parathyroid hormone-related protein is a positive regulator of keratinocyte growth factor expression by normal dermal fibroblasts. Mol Cell Endocrinol. 152:189197.

- Breuhaus, B.A. (2011). Disorders of the Equine Thyroid Gland. Vet Clin North Am Equine Pract. 27 (1):115-128.

- Buff, P.R.; Messer, N.T.; Cogswell, A.M.; Johnson, P.J.; Keisler, D.H.; Ganjama V.K. (2007) Seasonal and pulsatile dynamics of thyrotropin and leptin in mares maintained under a constant energy balance. Domestic Animal Endocrinol. 33: 430-436.

- Christensen, R.A.; Malinowski, K.; Massenzio, A.M.; Hafs, H.D.; Scanes, C.G. (1997). Acute effects of short-term feed deprivation and refeeding on circulating concentrations of metabolites, insulin-like growth factor $i$, insulin-like growth factor binding proteins, somatotropin, and thyroid hormones in adult geldings. J Anim Sci. 75:1351-1358.

- Cianchetta, S.; Bernardo, J.; Romeo, G.; Rhoden, K.J. (2010). Perchlorate transport and inhibition of the sodium iodide symporter measured with the yellow fluorescent protein variant YFP-H148Q/I152L. Toxicol Appl Pharmacol. 243: 372-380.

- Clutterbuck, A.L.; Harris, P.; Allaway, D.; Mobasheri, A; (2010). Matrix metalloproteinases in inflammatory pathologies of the horse. Vet J. 183: 27-38.

- Crockford, S.J. (2003). Thyroid rhythm phenotypes and hominid evolution: a new paradigm implicates pulsatile 
hormone secretion in speciation and adaptation changes. Comp Biochem Physiol AMol Integr Physiol. 135: 105-129.

- Dittrich, R.; Beckmann, M.W.; Oppelt, P.G.; Hoffmann, I; Lotz, L; Kuwert, T et al. (2011) Thyroid hormone receptors and reproduction. J Reprod Immunol. 90:58-66.

- Divers, J.T. (2008). Endocrine Testing in Horses: Metabolic Syndrome and Cushing's Disease. Equine Vet J. 28 (5): 315-316.

- Doige, C.E.; McLaughlin, B.G. (1981). Hyperplastic Goitre in Newborn Foals in Western Canada. Can. vet. J. 22: 4245.

- Durham, A. (2010). The Pharmacologic Basis for the Treatment of Endocrinopathic Laminitis. Vet Clin North Am Equine Pract. 26 (1): 115-128.

- Fazio, E; Medica, P.; Cravana, C.; Messineo, C.; Ferlazzo, A. (2007) Total and free iodothyronine levels of growing Thoroughbred foals: Effects of weaning and gender. Livestock Science. 110 (3): 207-213.

- Fazio, E.; Medica, P.; Cravana, C.; Messineo, C.; Ferlazzo, A. (2007). Total and free iodothyronine levels of growing Thoroughbred foals: Effects of weaning and gender. Department of Morphology, Biochemistry, Physiology and Animal Productions. Livestock Science. 110 (3): 207-213.

- Fitzgerald, B.P.; Davison, L.A. (1998). Thyroxine concentrations are elevated in mares which continue to exhibit estrous cycles during the nonbreeding season. Equine Vet J. 18 (1):48-51.

- Frank, N.; Sojka, J.; Messer, N.T.(2002) Equine thyroid dysfunction. Vet Clin Equine 18: 305-319.

- Frank, N. (2009). Equine Metabolic Syndrome. Vet Clin North Am Equine Pract. 29(5): 239-255.

- Ge'rard, N.; Duchamp, G.; Magistrini, M. (1999). Relationships between follicular fluid composition and follicular loocyte quality in the mare. Livestock Production Science 60:243-253.

- Geor, R.J. (2008). Metabolic Predispositions to Laminitis in Horses and Ponies: Obesity, Insulin Resistance and Metabolic Syndromes. Equine Vet J. 28 (12): 753-759.

- Geor, R.J. (2010). Nutrition and Exercise in the Management of Horses and Ponies at High Risk for Laminitis. Equine Vet J. 30 (9): 463-470.

- Gerlach, T.; Aurich, J.E. (2000). Regulation of seasonal reproductive activity in the stallion, ram and hamster. Anim Reprod Sci. 58:197-213.

- Glover, C.M.; Miller, L.M.; Dybdal, N.O.; Lopez, A. Duckett W.M.; McFarlane, D. (2009). Extrapituitary and Pituitary Pathological Findings in Horses with Pituitary Pars Intermedia Dysfunction: A Retrospective Study. Equine Vet J. 29 (39).

- Gray, H. (2000). Anatomy of the human body. 20va (ed.) New York: Bartleby. 
- Gürbüz, B.L.; Yalti, S.; Ficicioglu, C.; Tas, S. (2005). The relation of serum and follicular fluid leptin and ovarian steroid levels in response to induction of ovulation in in vitro fertilization cycles. Eur J Obstet Gynecol Reprod Biol 118: 214-218.

- Hubert, J.D.; Beadle, R.E.; Norwood, G. (2002). Equine anhidrosis. Vet Clin Equine 18 (2): 355-369.

- Hulbert, A.J. (2000). Thyroid hormones and their effects: a new perspective. Biol. Rev. 75:519-631.

- Hurcombe, S.D. (2011). Hypothalamic-Pituitary gland axis function and disfunction in horses. Vet Clin Equine. 27: 117.

- Hyypp, S. (2005). Endocrinal responses in exercising horses. Livestock Production Science 92: 113-121.

- Johnson, C.A. (2002). Thyroid Issues in Reproduction. Clin Tech Small Anim Pract. 17 (3): 129-132.

- Johnson, P.J.; Messer, N.T.; Slight, H.S.; Wiedmeyer, C.; Buff, P.; Ganjam. V.K. (2004). Endocrinopathic Laminitis in the Horse. Vet Clin Equine. 3 (1): 45-56.

- Kratzsch, J.; Pulzer, F. (2008). Thyroid gland development and defects. Best Pract Res Clin Endocrinol Metab. 22 (1): 57-75.

- Lucke, V.M. (1984). Lane JG.C-cell tumours of the thyroid in the horse. Eq Vet J. 16 (1):28-30.

- Malinowski, K.; Christensen, H.D. (1996). Hafs and Scanes C.G. Age and breed differences in thyroid hormones, insulin-like growth factor (IGF)-I and IGF binding proteins in female horses. J Anim Sci. 74: 1936-1942.

- McDermott, M.T.; Ridgway, C.E. (1998). Central hyperthyroidism. Endocrinol Metab Clin North Am. 27 (1): 187-203.

- Medica, P.; Cravana, C.; Fazio, E. D.V.M.; Ferlazzo, A. (2011). 24-hour endocrine profiles of quarter horses under resting conditions. Equine Vet J. 31: 35-40.

- Messer, N.T.; Riddle, T.; Traub-Dargatz J.L.; Dargatz, D.A.; Refsal, K.J.; Thompson, D.L. (1998). Thyroid Hormone Levels in Thoroughbred Mares and Their Foals at Parturition. Proceedings of the Annual Convention of the AAEP. 44: 248-251.

- Nagy, P.; Guillaume, D.; Daels, P. (2000). Seasonality in mares. Anim Reprod Sci 60: 245-262.

- Nicassio, M.; Aiudi, G.; Silvestre, F.; Matarrese, R.; De Sandro, A.S.; Lacalandra, G.M. (2008). Free thyroid hormone and cortisol levels in stallions during the breeding season. J Anim Sci. 107(3-4): 335-336.

- Petersen, A.D.; Schott, C.H. (2005) Cutaneous Markers of Disorders Affecting Adult Horses. Vet Clin North Am Equine Pract. 4 (4):324-338.

- Ramirez, S.; McClure, J.J.; Moore, R.M.; Wolfsheimer, K.J.; Gaunt, S.D.; Mirza M.H. et al (2010). Hyperthyroidism associated with a thyroid adenocarcinoma in a 21 -year-old gelding. $J$ Vet 
- Roser, J.F. (2008). Regulation of testicular function in the stallion: An intricate network of endocrine, paracrine and autocrine systems. Anim Reprod Sci. 107:179-196.

- Rudi's, P.; R'onai, Z.; Bartha, T. (2005). Thyroid hormone metabolism in the brain of domestic animals. Domest Anim Endocrinol. 29: 88-96.

- Sisson, S.; Grossman, J.D. (2000). Anatomía de los animales domésticos. 5a ed. Barcelona: Manson. S.A. pp.173-176.

- Slebodzi'nski. Ovarian iodide uptake and triiodothyronine generation in follicular fluid the enigma of the thyroid ovary interaction. Domestic Animal Endocrinol (2005). 29: 97103.

- Tahboub, R.; Arafah, B.M. (2009). Sex steroids and the thyroid. Best Pract Res Clin Endocrinol Metab. 23 (6): 769 780.

- Toribio, R.E.; Duckett, W.M. (2004). Equine Internal Medicine 2da ed. Estados Unidos de América: Saunders. pp. 1342-1355.

- Toribio, R.E. (2011). Endocrine Dysregulation in Critically II I Foals and Horses. Vet Clin North Am Equine Pract. 27 (1):35-47.

- Ueki, H.; Kowatari, Y.; Oyamada, T.; Oikawa, M.; Yoshikawa, H. (2004). Non-functional C-cell Adenoma in Aged Horses. J Comp Pathol 131(2-3):157-165.

- Walsh, D.N.; McGowan, C.M.; McGowan, T.; Lamb, S.V.; Schanbacher, B.J.Place, N.J. (2009). Correlation of Plasma Insulin Concentration with Laminitis Score in a Field Study of Equine Cushing's Disease and Equine Metabolic Syndrome. Equine Vet J. 29 (2): 87-94.

- Warner, M.H.; Beckett, G.J. (2010). Mechanisms behind the non-thyroidal illness syndrome: an update. J Endocrinol. 205:1-13. Intern Med 12: 475-7.

1. Laboratorio de Bioquímica Clínica y Patología Molecular, Departamento de Ciencias Básicas de la Salud, Universidad de Caldas. E-mail:jose.osorio_o @ucaldas.edu.co

2. Departamento de Salud Animal, Universidad de Caldas. 